\title{
Experimental Investigation of the Temperature Distribution in a Microwave- Induced Plasma Reactor
}

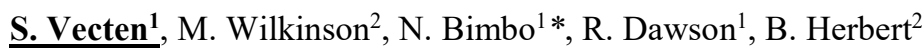 \\ First Author: Simon Vecten \\ Corresponding Author: Ben Herbert \\ Corresponding Author email: ben.herbert@stopford.co.uk \\ Corresponding Author telephone number: +44(0) 1524510604 \\ ${ }^{I}$ Engineering Department, Lancaster University, LA1 4YW, United-Kingdom \\ ${ }^{2}$ Stopford Projects Ltd, The Gordon Manley Building, Lancaster University, LA1 4YQ, United-Kingdom \\ *Present address: School of Chemistry, University of Southampton, SO17 1BJ, United Kingdom
}

List of Authors and email address:

- SimonVecten, s.vecten@lancaster.ac.uk

- Michael Wilkinson, michael.wilkinson@stopford.co.uk

- NunoBimbo,n.bimbo@soton.ac.uk

- RichardDawson,r.dawson@lancaster.ac.uk

- Ben Herbert, ben.herbert@stopford.co.uk

\begin{abstract}
It is urgent to reduce $\mathrm{CO}_{2}$ emissions to mitigate the impacts of climate change. The development of advanced conversion technologies integrated with plasma torches provides a path for the optimisation of clean energy recovery from biomass and wastes, thus substituting fossil fuels utilization. This article presents the temperature characterisation within a laboratory-scale microwave-induced plasma reactor operated with air, $\mathrm{H}_{2} \mathrm{O}$ and $\mathrm{CO}_{2}$ as the plasma working gases. The benefits associated with the plasma torch are highlighted and include rapid responses of the plasma and the temperature profile within the reactor to changing operating conditions. The average temperature near the side wall in the laboratoryscale reactor is proportional to the applied microwave power, ranging from $550^{\circ} \mathrm{C}$ at $2 \mathrm{~kW}$ to $850^{\circ} \mathrm{C}$ at $5 \mathrm{~kW}$, while significantly higher temperatures are locally present within the plasma plume. The described system demonstrates promising conditions that are ideal for effective energy recovery from biomass and wastes into clean fuel gas.
\end{abstract}

Keywords: Microwave-induced plasma torch, air, steam, carbon dioxide, advanced conversion technologies

\author{
Abbreviation: \\ ACT: Advanced Conversion Technologies \\ DC: Direct Current \\ IPCC: Intergovernmental Panel on Climate Change \\ MFC: Mass Flow Controller \\ MIP: Microwave-Induced Plasma \\ SLPM: Standard Litre Per Minute \\ SOFC: Solid Oxide Fuel Cell
}


The global surface temperature has abnormally increased by approximately $1{ }^{\circ} \mathrm{C}$ during the last century, causing modification of the climate system, a phenomenon commonly referred to as climate change [1]. According to the Intergovernmental Panel on Climate Change (IPCC), this phenomena is "increasing the likelihood of severe, pervasive and irreversible impacts for people and ecosystems", driven by sea-level rise and increases in the frequency and magnitude of extreme events (heat waves, droughts, floods, cyclones and wildfires) [2]. To limit the risks related to climate change, 189 Parties ratified the Paris Agreement in 2015, which aims to keep the global temperature rise below $2{ }^{\circ} \mathrm{C}$ above preindustrial levels [3]. The IPCC estimates this would equate to a global $\mathrm{CO}_{2}$ emissions reduction of $25 \%$ from 2010 levels by 2030 and reaching net zero around 2070 [4]. This will require major modifications for society, especially in the energy sector, where fossil fuel consumption is currently at its highest and represents more than $80 \%$ of the primary energy sources [5]. To meet this challenge, renewable energy generation must be rapidly implemented from wind and solar resources, but also from sustainably grown biomass. At the same time, waste generation has been ever increasing globally with implications for the environment and human health [6]. In fact, approximately $70 \%$ of waste worldwide is either landfilled or dumped [6], both of which are recognised as the least favoured waste management practices according to the waste hierarchy described in the European Directive 2008/98/EC on waste [7]. This work investigates the development of advanced conversion technologies (ACTs) integrated with microwave-induced plasma (MIP) torches, which has the potential to both efficiently generate renewable energy and fuels from biomass as well as to provide a solution for sustainable solid waste management.

\subsection{Plasma conversion technologies}

Gasification and pyrolysis are ACTs that have the potential to reduce $\mathrm{CO}_{2}$ emissions associated with energy generation from biomass and waste compared to that of incineration [8]. Gasification is a thermal treatment with partial oxidation from a controlled oxygen supply operating at elevated temperatures in the range $800-1,600^{\circ} \mathrm{C}$, and produces a synthetic gas (syngas) [9]. The syngas generated is rich in $\mathrm{CO}$ and $\mathrm{H}_{2}$, and can be used in a wide range of applications, such as electricity generation, as a precursor in the chemical industry or for the production of liquid and gaseous fuels [10]. In contrast, pyrolysis is the thermal dissociation of a solid feedstock in the absence of oxygen in the temperature range of $400-800^{\circ} \mathrm{C}$ [9]. The products of pyrolysis are char, pyrolysis oil, and pyrolysis gas, which can all be used for energy generation with yields varying according to the operating conditions [11].

The implementation of plasma torches in ACT systems presents an opportunity to enhance biomass and waste conversion while reducing harmful gaseous emissions [12]. In fact, plasma, sometimes referred as "the fourth state of matter", provides exceptional treatment conditions such as extremely high temperatures and very high concentrations of energetic and chemically active species (electrons, ions, excited species and photons) [13]. Plasma gasification technologies are generally based on DC (Direct Current) plasma torches, however such systems suffer from high operational costs, generally associated with the short lifespan of expensive electrodes in an oxidising environment $\left(<100 \mathrm{~h}\right.$ ) [14]. This issue can be overcome using MIP torches, capable of generating pure $\mathrm{H}_{2} \mathrm{O}$ plasma without degradation of any components [15].

\subsection{Review of MIP reactors}

Tang et al. [16] defined the different plasma reactor configurations including the plasma fixed bed reactor, the plasma moving bed reactor and the plasma entrained-flow bed reactor. The plasma fixed bed operates in batch sequence whereas the plasma moving-bed reactor is fitted with a feedstock inlet enabling continuous operation [16]. In the plasma entrainedflow reactor, the powdered feedstock is injected within the plasma flame [16].

Several studies investigated the potential of integrated MIP torches within ACT processes using different reactor configurations. The pyrolysis of small biomass and waste samples $<10 \mathrm{~g}$ has been described using Ar [17-19] and $\mathrm{N}_{2}$ [2022] as plasma working gases. However, the use of inert gases causes high dilution leading to the generation of syngas with an extremely low calorific value. It is therefore preferred to apply chemically reactive plasma gases to the feedstock such as air and $\mathrm{H}_{2} \mathrm{O}$. Most of the experimental MIP gasification studies have been undertaken with entrained-flow bed reactors where powdered coal [15, 23-25] or biomass [26, 27] is introduced within the high temperature plasma plume. However, Ho et al. [28] identified that the main challenge to improve MIP gasification performance using entrained-flow bed reactors is the fuel retention time. In fact, in the entrained-flow configuration, the feedstock is rapidly pushed away 
from the reaction zone by the high plasma velocity, thus limiting the conversion efficiency. In addition, the entrainedflow configuration requires pre-processing and size reduction of the feedstock, itself an energy intensive process.

The development of MIP fixed and moving bed reactors are alternative technologies that have received far less attention than entrained-flow reactors. Sanlisoy and Carpinlioglu $[29,30]$ recently developed a tubular MIP fixed bed reactor and investigated the gasification of a variety of fuels in an air plasma. Uhm et al. [31,32] described the only MIP moving bed reactor available in the literature. However, it is a demonstration-scale reactor fitted with two plasma torches with an operational specification of up to $75 \mathrm{~kW}$, and operates at a lower frequency of $915 \mathrm{MHz}$ compared to the usual $2.45 \mathrm{GHz}$ used at laboratory-scale. The reactor achieved complete coal conversion in steam plasma while generating a syngas rich in $\mathrm{H}_{2}$ and $\mathrm{CO}$ with volumetric concentration of $40 \%$ and $32 \%$ respectively $[31,32]$.

This study presents the temperature distribution measured within a laboratory-scale MIP moving-bed reactor, which to the best of the authors' knowledge, has not been previously described in the literature. Air, $\mathrm{CO}_{2}$ and $\mathrm{H}_{2} \mathrm{O}$ are three gases of interest in ACTs, and their use as plasma working gases are investigated here. The effect of applied microwave power and working gas flow rates on the temperature distribution are described.

\section{Materials and Methods}

The experimental rig can be divided in three main sections: the microwave plasma source and its components, the plasma working gas supply, and the plasma reactor. A block diagram of the experimental set-up is presented in Fig. 1.

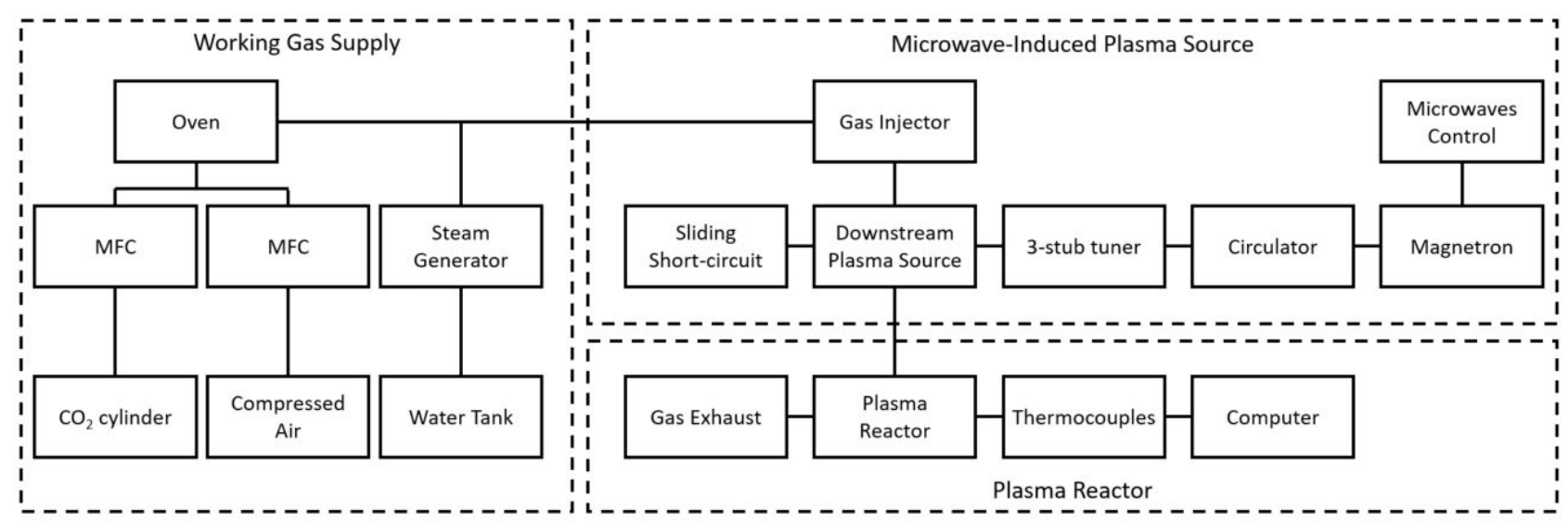

Fig. 1. Block diagram of the experimental set up.

\subsection{The microwave plasma source}

Plasma is generated in the MIP torch, which is initially a Downstream plasma source (Sairem SAS, Neyron, France). Microwaves are generated using a Sairem GMP G4 microwave generator composed of a high-voltage supply where the microwaves can be controlled. The microwave generator is connected to a magnetron head equipped with a circulator. The magnetron generates microwaves at a frequency of $2.45 \mathrm{GHz}$ up to $6 \mathrm{~kW}$ of forward power. The microwaves then propagate through WR340 waveguides equipped with a 3-stub tuner and a sliding short-circuit enabling the minimisation of the reflected microwave power to less than $1 \%$ of the forward microwave power whilst maintaining a stable plasma. Therefore, almost all the power in the microwaves is transmitted to the plasma and the overall efficiency of the system is almost equivalent to the conversion efficiency from electricity to microwaves that is in the range $60-70 \%$. The plasma working gas flows through a $35 \mathrm{~cm}$ long quartz tube with internal and external diameter of 25.6 and $30 \mathrm{~mm}$ respectively. The plasma is manually ignited by inserting a tungsten rod. The plasma is maintained by absorbing the microwave power within the downstream plasma source. The plasma plume propagates downstream and exits the quartz tube at its bottom tip. Fig. 2 presents an open-air plasma plume generated with the downstream plasma source. 


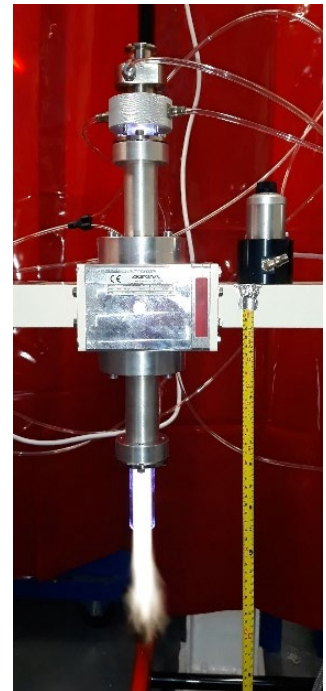

Fig. 2. Picture of the microwave-induced plasma torch in operation with air.

\subsection{Working gas supply}

The microwave plasma source can generate a stable plasma using air, $\mathrm{H}_{2} \mathrm{O}$ and $\mathrm{CO}_{2}$, as well as mixtures of these gases. Fig. 3 shows the plasma plume obtained for the three different plasma working gases studied. The flow rates of air and $\mathrm{CO}_{2}$ are regulated using mass flow controllers (MFC) (Alicat Scientific, Tucson AZ, USA) operating in the range 0 to 100 SLPM (standard litre per minute). A gas cylinder supplies the $\mathrm{CO}_{2}$ whereas air comes from the building compressed air lines. A precision steam generator (Cellkraft, Stockholm, Sweden) provides $\mathrm{H}_{2} \mathrm{O}$ at flow rates in the range 10 to $50 \mathrm{~g} / \mathrm{min}$ and at temperatures up to $200^{\circ} \mathrm{C}$.

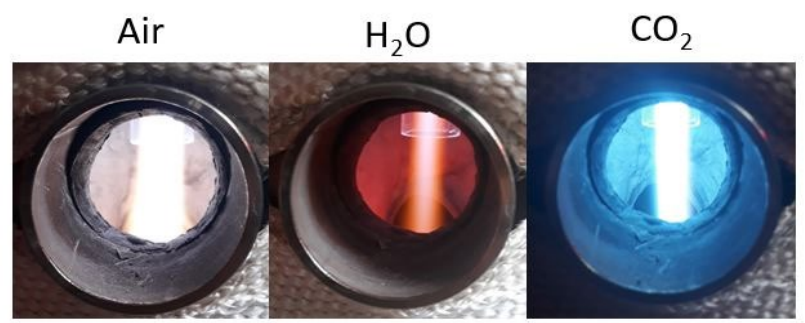

Fig. 3. Pictures of plasma plumes for different plasma working gases.

\subsection{The plasma reactor}

A plasma reactor has been designed and built for integration with the MIP torch. It is schematically presented in Fig. 4. The reactor has an internal diameter and length of approximately $15 \mathrm{~cm}$ and $35 \mathrm{~cm}$, respectively. It is internally insulated with a $3 \mathrm{~cm}$ layer of fire cement and externally using thermal webbing tape. The plasma reactor is equipped with a feedstock inlet, a safety line and a syngas outlet. The feedstock inlet is a 2 -inch pipe inclined by $45^{\circ}$ enabling the feedstock to be dropped into the reactor while the plasma torch is in operation. The feedstock can therefore be continuously inserted in the reactor in a moving bed configuration. Nevertheless, the feedstock inlet is not used in this study and is sealed off with a blind flange. The safety line is fitted with a rupture disc rated at 0.3 bar to manage the risk of overpressure in the reactor. The syngas outlet is a 2-inch pipe allowing the gas to exit near the top of the reactor. The top of the reactor is directly connected to the bottom of the downstream source. The plasma is released in the reactor at the bottom of the quartz tube.

Four type $\mathrm{K}$ thermocouples are located within the plasma reactor to investigate temperature distribution. The thermocouples are named T1, T2, T3 and T4 and are sited at $31 \mathrm{~cm}, 17 \mathrm{~cm}, 10 \mathrm{~cm}$ and $3 \mathrm{~cm}$ from the internal top of the reactor, respectively. The thermocouple T4 measures the temperature above where the plasma is released as the quartz tube extends about $4 \mathrm{~cm}$ from the top of the reactor. The average temperature in the reactor (TA) is calculated as the average of the four thermocouples T1, T2, T3 and T4. 
For the results presented in Section 3.1 to 3.4, the thermocouples protrude approximately $2 \mathrm{~cm}$ into the reactor beyond the refractory lining and measure the temperature close to the side wall. In Section 3.5, the thermocouples are repositioned to investigate the radial temperature gradient in the reactor. The distance between the tip of the thermocouple and the refractory lining is varied between 2 and $5 \mathrm{~cm}$. The temperatures presented in Section 3.5 are recorded by repeating a the following protocol: the reactor is first warmed-up using an applied microwave power of $5 \mathrm{~kW}$ for a period of 60 minutes, and then the temperature is recorded after 20 minutes of operation in the specific conditions of flow rate and applied microwave power.

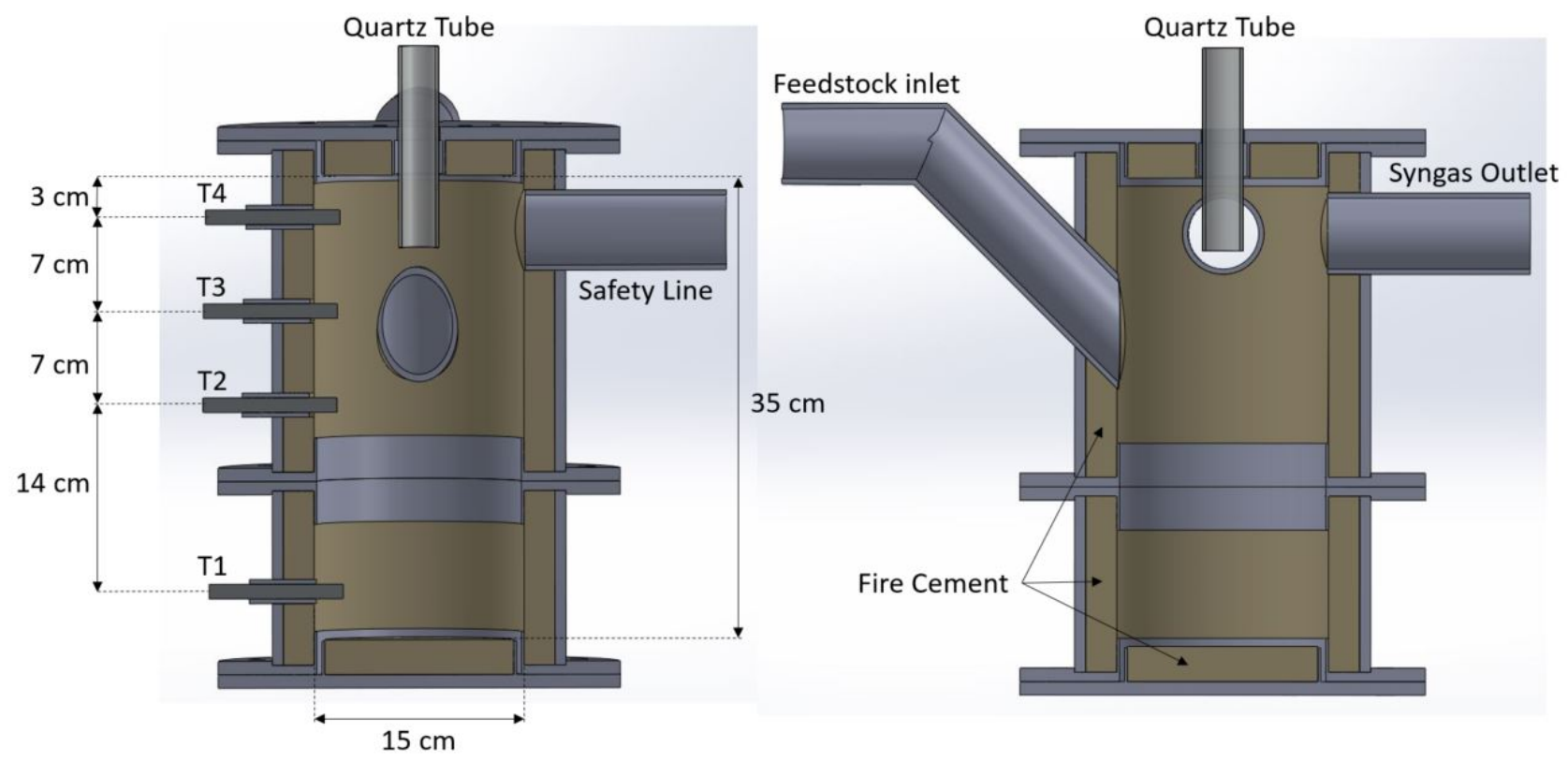

\section{Results and Discussion}

\subsection{Temperatures with air plasma}

This section presents the temperature distribution in the plasma reactor when operating the plasma torch with air.

Fig. 4. Schematic representation of the plasma reactor.

Fig. 5 depicts the temperature evolution over time when operating the plasma torch at constant conditions of 70 SLPM air and $5 \mathrm{~kW}$ applied microwave power. The graph indicates a very quick temperature increase during the first minutes of operation with a rate exceeding $150^{\circ} \mathrm{C}$ per minute. In fact, within the four first minutes, the average temperature (TA) rose from ambient $20^{\circ} \mathrm{C}$ to $650^{\circ} \mathrm{C}$. After 10 minutes of operation, the temperature profile evolves to a linear increase with a decreasing slope over time. TA increases from $750^{\circ} \mathrm{C}$ after 20 minutes to $890^{\circ} \mathrm{C}$ after almost 2 hours of operation. Nevertheless, the temperature increase rate diminishes below $1{ }^{\circ} \mathrm{C}$ per minute during the last 10 minutes but does not completely stabilise after 2 hours. The long temperature increase time is attributed to the large heat capacity of the fire cement layer thus taking time to warm up. Conversely, the heat stored in the fire cement refractory layer will be released when cooling down the inside of the reactor. The fire cement layer therefore has a great influence on the temperature measured within the reactor as it slows down heating and cooling rates, which also protects the metallic parts of the reactor from thermal shock. The experimental duration is limited to approximatively 2 hours because of the limited capacity of the cooling system in place for the magnetron operation.

Fig. 5 also provides information on the temperature distribution within the reactor. It is important to bear in mind that the temperatures T1, T2, T3 and T4 are measured close to the side wall, and thus provide a minimum on a cylindrical plane as higher temperatures are expected along the axis of the cylinder in line with the plasma plume. The highest temperatures are recorded by the thermocouples $\mathrm{T} 1$ and $\mathrm{T} 2$ at the bottom of the reactor. After 2 hours of operation, $\mathrm{T} 1$ 
temperatures are measured by the thermocouple T3, despite the fact that it is located closer to where the plasma plume is released, compared to T1 and T2. This observation can be attributed to the cone shape (horizontal expansion when moving down vertically) of the heat released by the plasma plume. Furthermore, measured temperatures by thermocouple T3 are generally in accordance with the average temperature calculated within the reactor. The lowest value is recorded by the thermocouple $\mathrm{T} 4$ at the top of the reactor, reaching up to $800^{\circ} \mathrm{C}$.

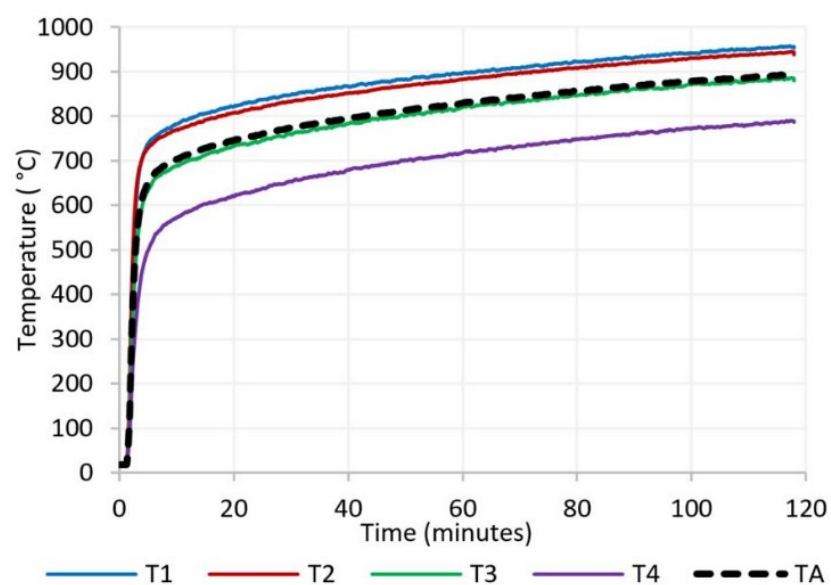

Fig. 5. Temperatures in reactor with 70 SLPM air plasma at $5 \mathrm{~kW}$ applied microwave power.

Fig. 6 presents the evolution of the temperature in the reactor when varying the applied microwave power at a constant air flow rate. The microwave power is modified with 20 minutes intervals in the range 2 to $5 \mathrm{~kW}$. It is evident that the temperature measured is proportional to the applied microwave power. In fact, a $1 \mathrm{~kW}$ increase in applied microwave power engenders a quick increase of TA in the range $80-100^{\circ} \mathrm{C}$ within less than 5 minutes. In addition, the temperature variations are similar at the different locations in the reactor and the microwave power does not affect the temperature distribution under the specific operating conditions presented in Fig. 6.

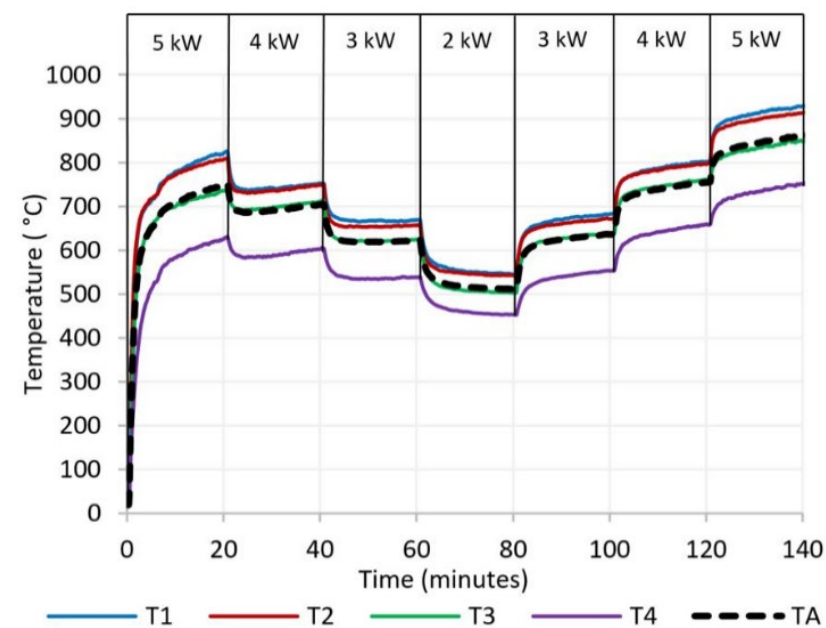

Fig. 6. Temperatures in reactor with 70 SLPM air plasma and varying applied microwave power.

The effects of the air flow rate are also investigated with variations in the range of 40 to 80 SLPM at a constant applied microwave power (Fig. 7). A fixed microwave power of $3 \mathrm{~kW}$ has been chosen as it enables plasma operation in a wider range of air flow rates. The maximum air flow rate is limited to 80 SLPM reflecting the maximum the compressed air supply could provide. The air supply was limited to 40 SLPM as low flow rate to power ratio can lead to the degradation of the quartz tube. Fig. 7 shows how the flow rate affects the temperature distribution. It is particularly visible at the lowest flow rate of 40 SLPM, with a sudden increase of temperature at T1, with decreases observed at both T2 and T3. This can be attributed to two main phenomena associated with the flow reduction: 1) a thinner plasma plume reduces the horizontal spreading of the heat; 2) lower turbulent flow pattern and air mixing in the reactor. Moreover, the temperature 
T4 is not significantly influenced by the change of air flow rate highlighting low turbulence in the reactor, especially in the upper section. Generally, an increase of 10 SLPM of the flow rate results in a decrease of the average temperature in the range $10-20^{\circ} \mathrm{C}$, which can be explained by a heat dilution effect. However, this is not evident at the lowest flow rate of 40 SLPM, because the large temperature disparities in the reactor makes TA more uncertain.

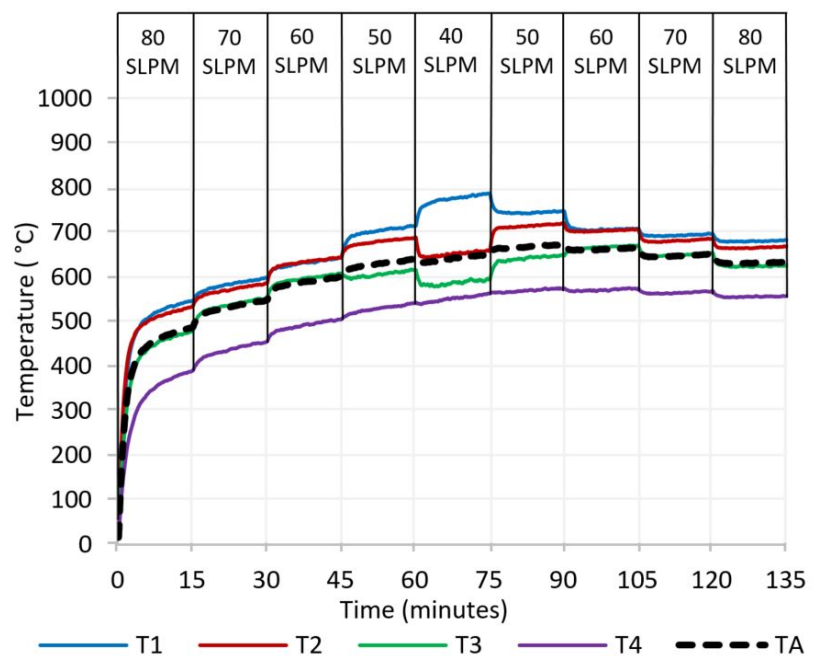

Fig. 7. Temperatures in reactor varying air flow rate at $3 \mathrm{~kW}$ microwave power.

\subsection{Temperatures with $\mathrm{H}_{2} \mathrm{O}$ plasma}

The main advantage of a microwave plasma torch is that it can be operated using carrier gases such as steam, which would otherwise corrode the electrodes of DC systems. This section of the manuscript presents the temperatures recorded in the reactor when operating with pure $\mathrm{H}_{2} \mathrm{O}$ plasma.

Fig. 8 presents the temperature distribution in the reactor by varying the applied microwave power when operating $\mathrm{H}_{2} \mathrm{O}$ plasma at a constant flow rate of $50 \mathrm{~g} / \mathrm{min}$. The lowest microwave power is $3 \mathrm{~kW}$ as it was empirically determined that a minimum of $2.5 \mathrm{~kW}$ was required to sustain a pure $\mathrm{H}_{2} \mathrm{O}$ plasma. Similarly, as for air, the temperatures are directly proportional to the applied microwave power. Nevertheless, lower temperature increases in the range $50-70^{\circ} \mathrm{C}$ per $1 \mathrm{~kW}$ microwave power are observed, whereas the increase was in the range $80-100^{\circ} \mathrm{C}$ when using air. Furthermore, contrary to air plasma, the applied microwave power affects the temperature distribution when operating with $\mathrm{H}_{2} \mathrm{O}$. Whereas $\mathrm{T} 1$ and $\mathrm{T} 2$ have very close values at $5 \mathrm{~kW}$, a decrease of the microwave power results in a more distinct reduction of the temperature at $\mathrm{T} 1$ than $\mathrm{T} 2$. In fact, at $3 \mathrm{~kW}$, the temperature at $\mathrm{T} 1$ is comparable with the temperature recorded at $\mathrm{T} 3$. This is attributed to a reduction of the length of the $\mathrm{H}_{2} \mathrm{O}$ plasma plume at low power, thus shifting the highest temperature region from the bottom to the middle of the reactor. 


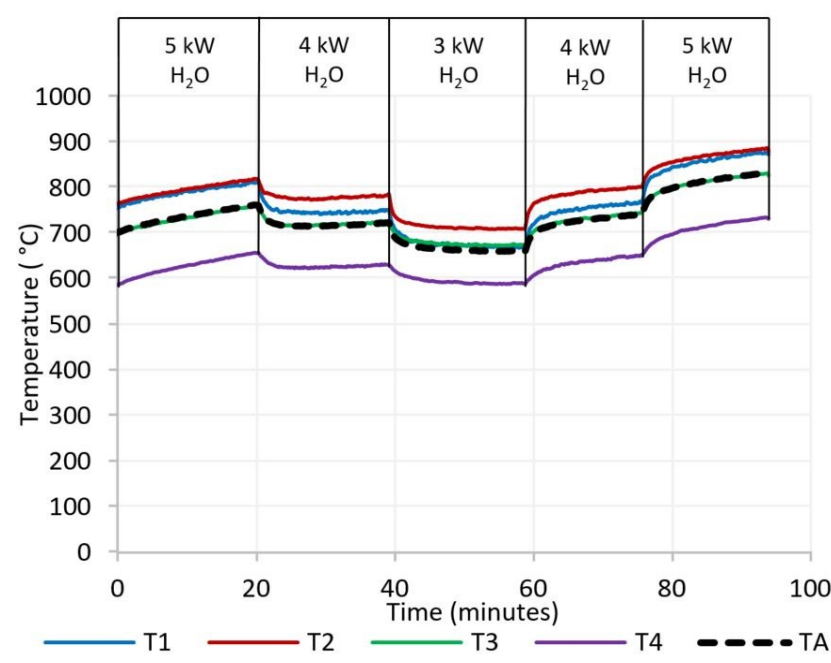

Fig. 8. Temperatures in reactor with $50 \mathrm{~g} / \mathrm{min}_{2} \mathrm{O}$ and varying applied microwave power.

The influence of the $\mathrm{H}_{2} \mathrm{O}$ flow rate is presented in Fig. 9 with variation between 30 and $50 \mathrm{~g} / \mathrm{min}$ at constant microwave power. This was undertaken at microwave power of $3 \mathrm{~kW}$ because operation at higher applied microwave power and low flow rate of $30 \mathrm{~g} / \mathrm{min}$ would damage the quartz tube. As can be seen in Fig. 9, the variation of $\mathrm{H}_{2} \mathrm{O}$ flow rate does not significantly affect the average temperature in the reactor. However, similarly as for air, lower $\mathrm{H}_{2} \mathrm{O}$ flow rates result in an increase in temperature measured at the bottom of the reactor. Thereby, the highest temperatures were measured by $\mathrm{T} 2$ at flow rate of $50 \mathrm{~g} / \mathrm{min}$ whereas the hottest region moves down to $\mathrm{T} 1$ at a flow rate of $30 \mathrm{~g} / \mathrm{min}$.

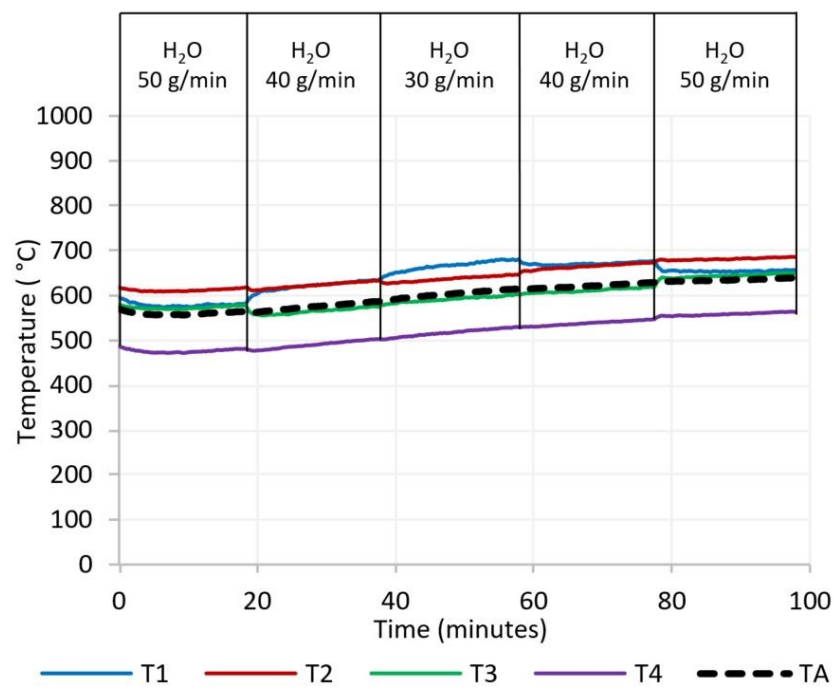

Fig. 9. Temperatures in reactor with varying $\mathrm{H}_{2} \mathrm{O}$ flow rate at constant microwave power of $3 \mathrm{~kW}$.

\subsection{Temperatures with $\mathrm{CO}_{2}$ plasma}

The third gas of interest in this study is $\mathrm{CO}_{2}$ because of its reforming properties that are of interests for biomass and wastes conversion to syngas. Moreover, $\mathrm{CO}_{2}$ is one of the main greenhouse gases and new utilisations of the gas could reduce fossil fuel derived emissions, thus mitigating climate change. The plasma torch is successfully operated with $\mathrm{CO}_{2}$ at considerably lower flow rates than air. In fact, as presented in Fig. 10, a stable $\mathrm{CO}_{2}$ plasma can be generated at a flow rate of 25 SLPM for an applied microwave power in the range $2-5 \mathrm{~kW}$. Operation at higher flow rates of up to 100 SLPM is possible but could not be sustained for long periods due to the limited capacity of the gas supply.

As presented in Fig. 10, the temperature T1 is substantially higher than T2 at high microwave powers of 4 and $5 \mathrm{~kW}$ reaching up to $1,000^{\circ} \mathrm{C}$. This phenomenon is typical for low flow rates as described previously for air and steam plasmas. However, at a lower microwave power of $2 \mathrm{~kW}$, the temperature at $\mathrm{T} 1$ drops lower than the temperatures observed at $\mathrm{T} 2$ 
and T3. It confirms the tendency, as seen for $\mathrm{H}_{2} \mathrm{O}$, that low microwave power causes a reduction of the size of the plasma plume limiting the heat propagation to the bottom of the reactor, which is further exacerbated at low flow rates. The average temperature was also found to be directly proportional to the applied microwave power, with a rapid temperature increase in the range $50-100^{\circ} \mathrm{C}$ per $\mathrm{kW}$. In addition, the temperature $\mathrm{T} 1$ is the most affected with temperature variation in the range $100-150^{\circ} \mathrm{C}$ per $1 \mathrm{~kW}$ change, highlighting non-homogeneous temperature distribution in the reactor, especially at low flow rates.

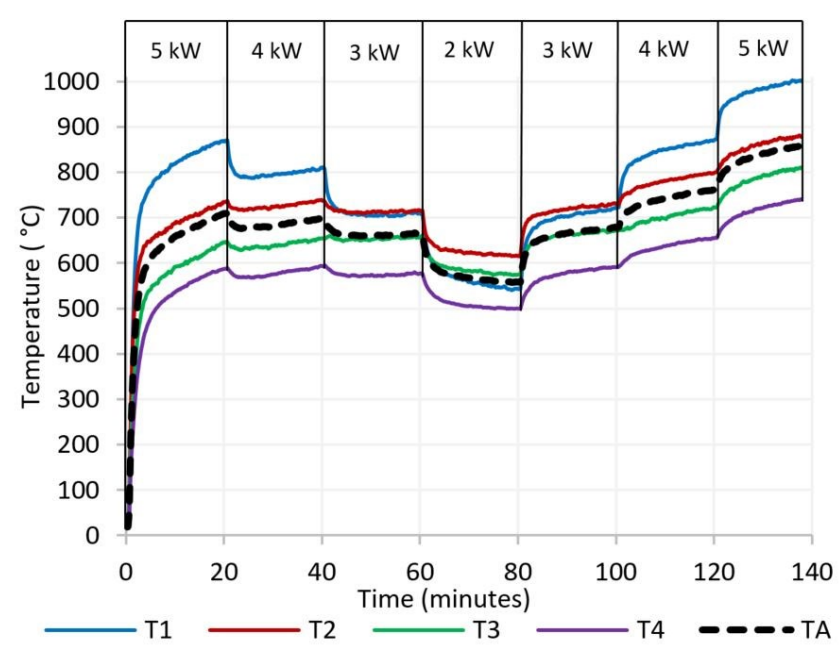

Fig. 10. Temperatures in reactor with $25 \mathrm{SLPM} \mathrm{CO}_{2}$ and varying applied microwave power.

\subsection{Comparison of plasma gases}

Fig. 11 presents the average temperature in the reactor when varying the applied microwave power for the three plasma working gases. The temperatures are taken after more than one hour of plasma operation and 20 minutes at the specific applied microwave power and flow rate, and uses the results presented in Fig. 6, 8 and 10. Whereas it was previously demonstrated that the measured temperatures are partially related to the gas flow rate and length of the experiment, Fig. 11 shows the main driver of the temperature is the applied microwave power. In fact, the average temperatures are very close for the three plasma working gases with maximum differences of $50^{\circ} \mathrm{C}$ at microwave powers above $3 \mathrm{~kW}$. At a lower microwave power of $2 \mathrm{~kW}$, higher temperature differences are noted, explained by thermal stratification in the reactor causing uncertainties in the calculated averages. Generally, the average temperatures close to the side wall of the reactor are approximately $550,650,750$ and $850^{\circ} \mathrm{C}$ at an applied microwave power of $2,3,4$ and $5 \mathrm{~kW}$, respectively.

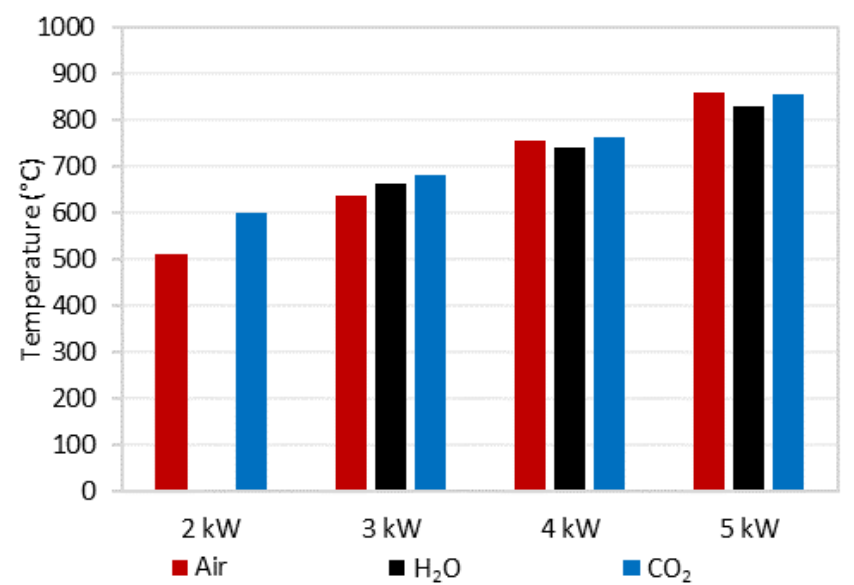

Fig. 11. Average temperature in reactor varying applied microwave power for $\mathrm{H}_{2} \mathrm{O}$, air and $\mathrm{CO}_{2}$ at flow rate of $50 \mathrm{~g} / \mathrm{min}, 70 \mathrm{SLPM}$ and 25 SLPM respectively. 
The major drawback of plasma torches is their high energy consumption, which can have a detrimental impact on the overall process efficiency [12]. Hence, it is essential to optimise the operating conditions according to feedstock characteristics. In fact, the plasma ACT process can be applied to a wide range of wastes including biomass wastes, refuse derived fuel (such as mixtures of plastics, paper, wood and dried organic materials), hazardous wastes, used tyres, paper mill wastes, medical wastes or sewage sludge wastes $[14,33]$. The performance and optimal operating conditions depend on the waste specific properties such as elemental composition, lower heating value (LHV), ash content, volatile matter content, contaminants, bulk density and size [34]. These properties influence the temperature required for effective solid conversion.

The experimental results highlight the direct relationship between the applied microwave power and temperature in the reactor. It provides control of the processing environment, thus enabling real-time optimisation of the system. The temperature is also affected by the occurring chemical reactions driven by the nature of the plasma working gas. The use of air increases the temperature and thus conversion through exothermic oxidation reactions, but reduces the calorific value of the generated gas because of $\mathrm{N}_{2}$ dilution as well as fuel oxidation into $\mathrm{CO}_{2}$ and $\mathrm{H}_{2} \mathrm{O}$ [34]. $\mathrm{H}_{2} \mathrm{O}$ and $\mathrm{CO}_{2}$ plasma treatments enhance reforming reactions and generates syngas with a higher heating value [34]. However, reforming reactions are endothermic and would rely on the heat provided by the plasma, thus requiring higher energy consumption of the plasma torch.

Numerical models are useful tools to theoretically optimise the operating conditions of plasma ACT processes and can be used to identify a balance between feedstock conversion and electricity consumption by operating with a mixture of plasma working gases. For example, Ismail et al. [35] determined that an equivalence ratio (ratio of oxygen in reactor to the stoichiometric amount of oxygen required for full feedstock oxidation) of 0.3 and a steam to fuel ratio of 0.5 were the most favourable conditions for high-quality syngas generation from municipal solid wastes in a plasma fixed-bed gasification reactor. In contrast, this work provides a first characterisation of our MIP reactor that will enable the conversion efficiency to be experimentally studied at laboratory scale by varying the operating conditions for different feedstocks.

\subsection{Radial temperature gradients}

To investigate the radial temperature gradient within the reactor, the experiments were repeated, and temperature measurements were made at distances between $2-5 \mathrm{~cm}$ away from the side wall of the reactor. Fig. 12 presents the temperature recorded for different positions of the thermocouples with 70 SLPM air and an applied microwave power of $5 \mathrm{~kW}$. As expected, higher temperatures were measured when moving the thermocouples towards the centre of the reactor. In fact, the temperatures recorded at $\mathrm{T} 1$ show a relatively linear increase, ranging between $10-20^{\circ} \mathrm{C}$ per $1 \mathrm{~cm}$ displacement to the centre of the reactor. A similar trend is observed at $\mathrm{T} 2$ and $\mathrm{T} 3$ whereby the thermocouples were positioned between 2 and $4 \mathrm{~cm}$ from the side wall. However, the temperature drastically increased at T2 and T3 when moving the thermocouples $5 \mathrm{~cm}$ from the side wall towards the centre of the reactor. At this position, the thermocouples are closest to the plasma plume, with the highest temperatures measured exceeding $1050^{\circ} \mathrm{C}$ at an applied microwave power of $5 \mathrm{~kW}$. Similar trends were achieved at $\mathrm{T} 3$ with the highest temperatures recorded when operating the plasma torch with 70 SLPM air and applied microwave powers of 2, 3 and $4 \mathrm{~kW}$.

To avoid damage to the thermocouples at $\mathrm{T} 3$, given the expected exponential increase in temperature towards the centre of the plasma plume, a maximum measurement distance of $5 \mathrm{~cm}$ from the reactor wall was instated. In fact, the temperature distribution is characterised by extremely high temperatures, as a result of the plasma plume, at the top centre of the reactor. The temperature was found to decrease when moving away from the plasma plume as described. Whilst the temperature around the plasma plume can be measured using thermocouples, the temperature within the plasma is usually estimated by comparing optical emission spectroscopy measurements with simulated spectra. A previous study from the authors showed that the temperature in $\mathrm{H}_{2} \mathrm{O}$ and $\mathrm{CO}_{2}$ plasmas ranged from approximatively $6,000^{\circ} \mathrm{C}$ where the plasma is generated to $2,300^{\circ} \mathrm{C} 14 \mathrm{~cm}$ downstream of the plasma plume [36]. Similar temperatures are expected in air plasma [37]. Moreover, it was demonstrated that the temperature in the centre of the plasma was not significantly influenced by the applied microwave power [36]. In this study, it was demonstrated that an increase in applied microwave power resulted in a greater proportion of working gas being ionised, resulting in an enlargement of the plasma plume diameter within the quartz tube. The temperatures recorded in the reactor are therefore proportional to the applied 
microwave power mainly because of the impact it has on the ratio of hot to cold gasses in the quartz tube as opposed to a change in plasma temperature.

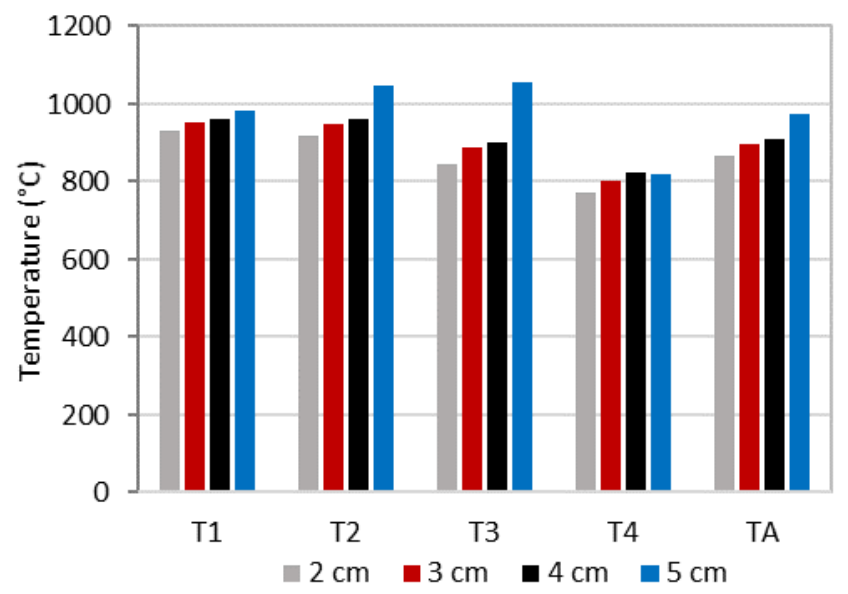

Fig. 12. Temperature in reactor with 70 SLPM air and $5 \mathrm{~kW}$ applied microwave power varying the distance of the thermocouples to the refractory lining between 2 and $5 \mathrm{~cm}$.

Fig. 13 presents the temperatures recorded in the reactor, across the different thermocouple positions, with 40 SLPM air at $3 \mathrm{~kW}$ applied microwave power. As depicted in Fig. 12, highest temperatures were recorded close to the centre of the reactor. Nevertheless, even when the thermocouples were positioned $5 \mathrm{~cm}$ from the side wall, the highest temperatures were recorded at $\mathrm{T} 1$ and not $\mathrm{T} 3$ as experienced with higher air flow rate. This confirms that lower plasma gas flow rates tend to reduce the horizontal heat expansion along the plasma plume resulting in higher temperatures at the bottom of the reactor.

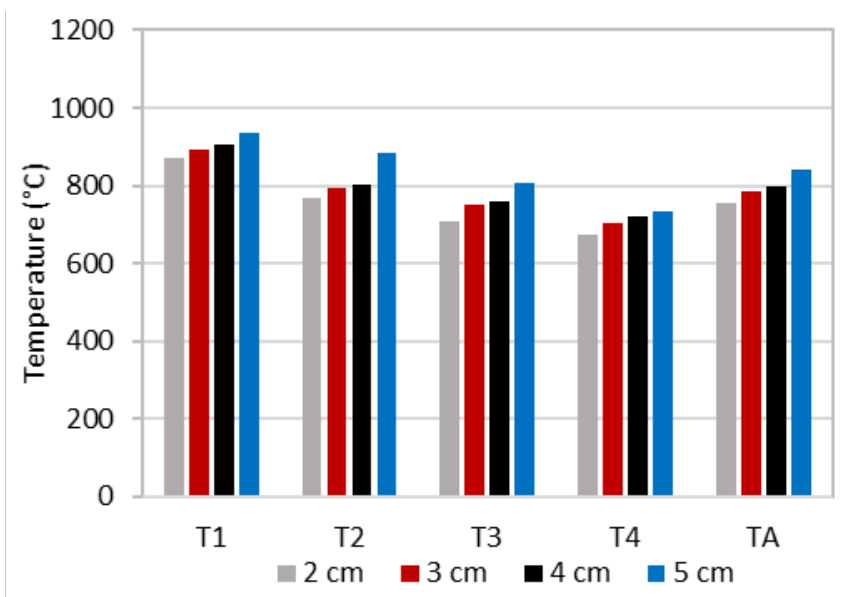

Fig. 13. Temperature in reactor with 40 SLPM air and $3 \mathrm{~kW}$ applied microwave power varying the distance of the thermocouples to the refractory lining between 2 and $5 \mathrm{~cm}$.

\subsection{Benefits of the plasma reactor}

The experimental study shows that temperatures ranging from $500^{\circ} \mathrm{C}$ to $1,050^{\circ} \mathrm{C}$ are achieved within the presented plasma reactor. The system is thus able to generate appropriate temperatures above $600^{\circ} \mathrm{C}$ that are required for efficient conversion of solid carbon and light hydrocarbons [34]. The solid fuel can be injected in the reactor through the feedstock inlet and sit at the bottom of the reactor, where some of the highest temperatures were recorded. The reactor configuration thus enables long fuel retention time that should enhance the conversion efficiency [28]. Nevertheless, one of the main issues with ACT is the presence of tars contaminating the generated gas [14]. Tars are a complex mixture of condensable 
must pass close to the plasma plume to exit the reactor at the top, substantial tars reforming is expected due to the plasma's exceptional properties. First, the plasma's extremely high temperatures will enhance endothermic steam and dry reforming reactions as well as the thermal cracking reactions of tars. In addition, plasma is composed of very chemically reactive species including electrons, ions, excited molecules and photons. These species are able to stimulate chain processes in a way that cannot be accomplished in conventional chemistry [13]. This effect is usually designated as plasma catalysis as it enhances chemical reaction rates in a similar manner to the presence of a catalyst [13]. A previous study by the authors on the same system demonstrates that active plasma species (e.g. $\mathrm{O}, \mathrm{OH}$ and $\mathrm{H}$ radicals in $\mathrm{H}_{2} \mathrm{O}$ plasma) are still present $14 \mathrm{~cm}$ below the plasma plume [36]. The dissociation of $\mathrm{H}_{2} \mathrm{O}$ in plasma is dominated by $\mathrm{H}, \mathrm{O}, \mathrm{OH}, \mathrm{H}_{2}$ and $\mathrm{O}_{2}$ species, whereas $\mathrm{CO}_{2}$ mainly dissociates into $\mathrm{CO}, \mathrm{C}, \mathrm{O}, \mathrm{C}_{2}$ and $\mathrm{O}_{2}[39,40]$. The benefits of $\mathrm{H}_{2} \mathrm{O}$ and $\mathrm{CO}_{2}$ dissociation in MIP is that it provides oxygen for full and partial-oxidation reactions that favour fuel conversion, whilst generating additional $\mathrm{H}_{2}$ and $\mathrm{CO}$ which serves to further enrich the product syngas [39, 40]. Several experimental studies have shown high tar conversion for syngas cleaning using MIP torches [41]. However, those experiments investigate the application of MIP reforming in a second step process for gas cleaning following conventional ACT. Therefore, tar conversion might be significantly lowered when the MIP torch is used for both gasification and gas cleaning in the same reactor. The MIP moving bed reactor described in this study will enable the experimental investigation of the quantity and composition of tars present in syngas by varying the feedstock composition and operating conditions.

The MIP-ACT process can be completed with a syngas cleaning step to meet the downstream requirements for syngas quality. Tars are conventionally removed at low temperatures using wet scrubbing processes, which presents drawbacks in relation to a reduction in efficiency due to syngas cooling or the additional costs incurred to treat and dispose of the tar contaminants [42]. Another approach is the in-situ decomposition of tars into valuable $\mathrm{CO}$ and $\mathrm{H}_{2}$ that will serve to enrich the generated syngas. This can be achieved at elevated temperatures using catalysts, however their costs and rapid deactivation limit their use [42], or through virtue of internal cracking of the tars within the reactor itself.

\subsection{Scale-up and deployment}

The commercialisation of ACT technologies can be limited by the expensive gas cleaning required to meet downstream requirements [34]. The use of a microwave plasma torch should improve the quality of the gas generated, thus reducing the size and cost of the gas cleaning step. Processes involving MIP torches have been widely investigated in laboratories but can also be scaled-up for industrial applications [28]. The first possibility is to integrate a multitude of plasma torches into one large reactor, which provides the advantage of improved heat distribution within the reactor. Moreover, MIP torches with capacity up to $100 \mathrm{~kW}$ are commercially available at a lower frequency of $915 \mathrm{MHz}$ whereas systems at $2.45 \mathrm{GHz}$ are generally limited to $15 \mathrm{~kW}$ [43]. One of the main advantages of higher capacity microwave generators is their improved efficiency. Whereas the conversion efficiency from electricity to microwaves is circa $70 \%$ at frequency of $2.45 \mathrm{GHz}$, it is considerably improved at lower frequency of $915 \mathrm{MHz}$ and can reach up to $88 \%$, therefore positively affecting the overall efficiency of the proposed MIP-ACT process when scaling-up [44]. Uhm et al. described the high efficiency of a coal gasification process using two MIP torches of $75 \mathrm{~kW}$ operating at frequency of $915 \mathrm{MHz}$, and capable of generating $500 \mathrm{~kW}$ of syngas [31,32]. In addition, high power magnetrons between 0.5 and $1 \mathrm{MW}$ could potentially be developed for large scale applications at low frequency of $433.96 \mathrm{MHz}$ [43].

The gas generated from industrial microwave plasma ACT systems could be used in various downstream applications, including liquid fuel production, chemicals production or electricity generation, which all enable substitution of fossil fuels and could mitigate against climate change [14]. Electricity generation can be undertaken using gas engines, gas turbines or solid oxide fuel cells (SOFC). The emerging SOFC systems have high electrical efficiency up to $65 \%$ and could engender a technology shift, by making integrated MIP-ACT-SOFC systems more efficient, especially at relatively small scales below $1 \mathrm{MW}$ [45]. In addition, such system enable a multitude of integration options. Song and Chun demonstrate that up to $65 \%$ of $\mathrm{CO}_{2}$ could be converted to combustible $\mathrm{CO}$ in a MIP torch and in the presence of biomass char [46]. Therefore, parts of the exhaust of a downstream electricity generation device, rich in carbon dioxide, could be recycled back into the plasma torch, thus reducing the $\mathrm{CO}_{2}$ emissions per unit of energy generated. Perna et al. [47] affirmed that an advanced power plant combining plasma gasification and SOFC could achieve high electrical efficiencies in the range $35-45 \%$, substantially higher than the average $20 \%$ of conventional incineration power plant with a steam turbine. The plasma ACT system has the potential to recover energy from wastes with high efficiency and could be deployed where the wastes are generated, thus providing clean energy for on-site use. At the same time, pollution and 
costs associated with waste transportation can be avoided. Our research suggests that, as part of the transition to a more sustainable circular economy that is demanded by the European Commission [48], the use of small scale, compact, decentralised systems should be considered.

\section{Conclusion}

This work presents the temperature measurement in a MIP moving-bed reactor at laboratory scale designed for waste and biomass energy recovery. Beside the extreme temperatures within the plasma plume, high temperatures are recorded with values approaching $1,000^{\circ} \mathrm{C}$ at the bottom of the reactor. The study shows here that the average temperature near the side wall within the laboratory scale system is proportional to the applied microwave power and varies from $550^{\circ} \mathrm{C}$ at $2 \mathrm{~kW}$ to $850^{\circ} \mathrm{C}$ at $5 \mathrm{~kW}$. While the temperatures recorded are of the same order for the three plasma working gases studied, high flow rates and applied microwave power results in more homogeneous temperature distribution within the reactor, which should be improved through further design. Our experimental results suggest that control of operating parameters on a short temporal resolution provides further advantages when using an MIP torch for the direct management of the processing environment. This study provides important results for the preparation of biomass and wastes plasma ACT experiments that will enable the efficiency of the process and the quality of the syngas generated to be empirically determined. Ideal conditions are described for effective conversion of organic solid into clean combustible gas, which could balance the high energy consumption of the plasma torch. The proposed plasma ACT reactor has the potential to be developed as part of the transition to more sustainable solid waste management practices and could contribute towards a more complete circular economy.

\section{Acknowledgements}

This work was supported by the European Regional Development Fund (ERDF) through the Centre for Global EcoInnovation in partnership between Lancaster University and Stopford Projects Ltd (grant number 19R16P01012). This research was also supported by Innovate UK (grant number 133710).

\section{References}

[1] NOAA National Centers for Environmental information, Climate at a Glance: Global Time Series. https://www.ncdc.noaa.gov/cag/, 2020 (accessed 25 April 2020).

[2] IPCC, Climate Change 2014: Synthesis Report. https://www.ipcc.ch/report/ar5/syr/, 2014 (accessed 14 February 2020).

[3] United Nations Climate Change, The Paris Agreement. https://unfccc.int/process-and-meetings/the-parisagreement/the-paris-agreement, 2015 (accessed 26 March 2020).

[4] IPCC, Special Report: Global Warming of $1.5^{\circ} \mathrm{C}$. https://www.ipcc.ch/sr15/chapter/spm/, 2018 (accessed 25 April 2020).

[5] BP, Statistical Review of World Energy. https:/www.bp.com/en/global/corporate/energy-economics/statisticalreview-of-world-energy.html, 2019 (accessed 25 April 2020).

[6] S. Kaza, L. Yao, P. Bhada-Tata, F. Van Woerden, K. Ionkova, What a waste 2.0 : a global snapshot of solid waste management to 2050, World Bank Group, Washington, 2019. https://doi.org/10.1596/978-1-4648-1329-0

[7] European Parliament and the Council of the European Union. Directive 2008/98/EC of the European Parliament and of the Council on waste and repealing certain Directives. https://eur-lex.europa.eu/legalcontent/EN/TXT/?uri=CELEX:32008L0098, 2008 [accessed 14 February 2020].

[8] T.P.T Pham, R. Kaushik, G. Parshetti, R. Mahmood, R. Blasubramanian, Food waste-to-energy conversion technologies: Current status and future directions, Waste Management 38 (2015) 399-408. https://doi.org/0.1016/j.wasman.2014.12.004

[9] A. Kumar, S.R. Samadder, A review on technological options of waste to energy for effective management of municipal solid waste, Waste Management 69 (2017) 407-422. https://doi.org/407-422. 10.1016/j.wasman.2017.08.046

[10] R. Luque, J.G. Speight, Gasification for synthetic fuel production: fundamentals, processes and applications, $1^{\text {st }}$ e, Woodhead Publishing, Cambridge, 2015.

[11] L. Lombardi, E. Carnevale, A. Corti, A review of technologies and performances of thermal treatment systems for energy recovery from waste, Waste Management 37 (2015) 26-44. https://doi.org/10.1016/j.wasman.2014.11.010 
[12]B. Ruj, S. Ghosh, Technological aspects for thermal plasma treatment of municipal solid waste-A review, Fuel Processing Technology 126 (2014) 298-308. https://doi.org/10.1016/j.fuproc.2014.05.011

[13] A. Fridman, Plasma chemistry, 2008. https://doi.org/10.1017/CBO9780511546075

[14]F. Fabry, C. Rehmet, V. Rohani, L. Fulcheri, Waste Gasification by Thermal Plasma: A Review, Waste and Biomass Valorization 5 (2013) 421-439. https://doi.org/10.1007/s12649-013-9201-7

[15]D.H. Shin et al., A pure steam microwave plasma torch: Gasification of powdered coal in the plasma, Surface \& Coatings Technology 228 (2013) 520-523. https://doi.org/10.1016/j.surfcoat.2012.04.071

[16] L. Tang, H. Huang, H. Hao, K. Zhao, Development of plasma pyrolysis/gasification systems for energy efficient and environmentally sound waste disposal, Journal of Electrostatics $71 \quad(2013)$ 839-847. https://doi.org/10.1016/j.elstat.2013.06.007

[17] C.J. Lupa, R.S. Wylie, A. Shaw, A. Al-Shamma'a, J.A. Sweetman, B.M.J Herbert, Experimental analysis of biomass pyrolysis using microwave-induced plasma, Fuel Processing Technology 97 (2012) 79-84. https://doi.org/10.1016/j.elstat.2013.06.007

[18] C.J. Lupa, R.S. Wylie, A. Shaw, A. Al-Shamma'a, J.A. Sweetman, B.M.J Herbert, Gas evolution and syngas heating value from advanced thermal treatment of waste using microwave-induced plasma, Renewable Energy 50 (2013) 1065-1072. https://doi.org/10.1016/j.renene.2012.09.006

[19] H. Sekiguchi and T. Orimo, Gasification of polyethylene using steam plasma generated by microwave discharge, Thin Solid Films 457 (2004) 44-47. https://doi.org/10.1016/j.tsf.2003.12.035

[20] Y.C. Lin, T.Y. Wu, S.R. Jhang, P.M. Yang, Y.H. Hsiao, Hydrogen production from banyan leaves using an atmospheric-pressure microwave plasma reactor, Bioresource Technology 161 (2014) 304-309. https://doi.org/10.1016/j.biortech.2014.03.067

[21] K.C. Lin, Y.C. Lin, Y.H. Hsiao. Microwave plasma studies of Spirulina algae pyrolysis with relevance to hydrogen production, Energy 64 (2014) 567-574. https://doi.org/10.1016/j.energy.2013.09.055

[22] Y.C. Lin, T.Y. Wu, W.Y. Liu, Y.H. Hsiao, Production of hydrogen from rice straw using microwave-induced pyrolysis, Fuel 119 (2014) 21-26. https://doi.org/10.1016/j.fuel.2013.11.046

[23] S.J. Yoon and J.G. Lee, Hydrogen-rich syngas production through coal and charcoal gasification using microwave steam and air plasma torch, International Journal of Hydrogen Energy 37 (2012) 17093-17100. https://doi.org/10.1016/j.ijhydene.2012.08.054

[24] S.J. Yoon,J. Goo Lee, Syngas production from coal through microwave plasma gasification: Influence of oxygen, steam, and coal particle size, Energy and Fuels 26 (2012) 524-529. https://doi.org/10.1021/ef2013584

[25] Y.C. Hong et al., Syngas production from gasification of brown coal in a microwave torch plasma. Energy 47 (2012) 36-40. https://doi.org/10.1016/j.energy.2012.05.008

[26] G. Sturm, A. Munoz, P. Aravind, G. Stefanidis, Microwave-Driven Plasma Gasification for Biomass Waste Treatment at Miniature Scale, IEEE Transactions on Plasma Science 44 (2016) 670-678. https://doi.org/10.1109/TPS.2016.2533363

[27] E. Delikonstantis et al., Biomass gasification in microwave plasma: An experimental feasibility study with a side stream from a fermentation reactor, Chemical Engineering and Processing - Process Intensification 141 (2019). https://doi.org/10.1016/j.cep.2019.107538

[28] G.S. Ho, H.M. Faizal, F.N. Ani, Microwave induced plasma for solid fuels and waste processing: A review on affecting factors and performance criteria, Waste Management $69 \quad$ (2017) 423-430. https://doi.org/10.1016/j.wasman.2017.08.015

[29] A. Sanlisoy and M.O. Carpinlioglu, Preliminary measurements on microwave plasma flame for gasification. Energy, Ecology and Environment 3 (2018) 32-38. https://doi.org/10.1007/s40974-017-0063-x

[30]A. Sanlisoy and M.O. Carpinlioglu, Microwave Plasma Gasification of a Variety of Fuel for Syngas Production, Plasma Chemistry and Plasma Processing 39 (2019) 1211-1225. https://doi-org/10.1007/s11090-019-10004-X

[31] H.S Uhm, Y.H. Na, Y.C. Hong, D.H. Shin, C.H. Cho, Y.K. Park, High-Efficiency Gasification of Low-Grade Coal by Microwave Steam Plasm,. Energy Fuels 28 (2014) 4402-4408. https://doi.org/10.1021/ef500598u

[32] H.S. Uhm, Y.H. Na, Y.C. Hong, D.H. Shin, C.H. Cho, Production of hydrogen-rich synthetic gas from low-grade coals by microwave steam-plasmas, International Journal of Hydrogen Energy 39 (2014) 4351-4355. https://doi.org/10.1016/j.ijhydene.2014.01.020

[33] J. Heberlein, A.B. Murphy, Thermal plasma waste treatment, Journal of Physics D: Applied Physics 41 (2008). https://doi.org/10.1088/0022-3727/41/5/053001

[34] U. Arena, Process and technological aspects of municipal solid waste gasification A review, Waste Management 32 (2012) 625-639. https://doi.org/10.1016/j.wasman.2011.09.025

[35] T.M. Ismail, A. Ramos, M. Abd El-Salam, E. Monteiro, A. Rouboa, Plasma fixed bed gasification using an Eulerian model, International Journal of Hydrogen Energy $44 \quad$ (2019) 28668-28684. https://doi.org/10.1016/j.ijhydene.2019.08.035 
[36] S. Vecten, M. Wilkinson, A. Martin, A. Dexter, N. Bimbo, R. Dawson, B. Herbert, Experimental study of steam and carbon dioxide microwave plasma for advanced thermal treatment application, Energy 207 (2020) 118086. https://doi.org/10.1016/j.energy.2020.118086

[37] L. Su, R. Kumar, B. Ogungbesan, M. Sassi, Experimental investigation of gas heating and dissociation in a microwave plasma torch at atmospheric pressure, Energy conversion and management 78 (2014) 695-703. https://doi.org/10.1016/j.enconman.2013.12.001

[38] P.V. Aravind, W. de Jong, Evaluation of high temperature gas cleaning options for biomass gasification product gas for Solid Oxide Fuel Cells, Progress in Energy and Combustion Science 38 (2012) 737-764. https://doi.org/10.1016/j.pecs.2012.03.006

[39] H.S. Uhm, J.H. Kim, Y.C. Hong, Disintegration of water molecules in a steam-plasma torch powered by microwaves, Physics of Plasmas 14 (2007). https://doi-org/10.1063/1.2749225

[40] S.K. Hyoung, H.S. Uhm, Y.C. Hong, E.H. Choi, Disintegration of Carbon Dioxide Molecules in a Microwave Plasma Torch, Scientific Reports 5 (2015). https://doi.org/10.1038/srep18436

[41] F. Saleem, J. Harris, K. Zhang, A. Harvey, Non-thermal plasma as a promising route for the removal of tar from the product gas of biomass gasification - A critical review, Chemical Engineering Journal 382 (2020). https://doi.org/10.1016/j.cej.2019.122761

[42] N. Abdoulmoumine, S. Adhikari, A. Kulkarni, S. Chattanathan, A review on biomass gasification syngas cleanup, Applied Energy 155 (2015) 294-307. https://doi.org/10.1016/j.apenergy.2015.05.095

[43] J.F. De La Fuente, A.A. Kiss, M.T. Radoiu, G.D. Stefanidis, Microwave plasma emerging technologies for chemical processes, Journal of Chemical Technology \& Biotechnology 92 (2017) 2495-2505. https://doiorg $/ 10.1002 / \mathrm{jctb} .5205$

[44] A.S. Gilmour, Klystrons, traveling wave tubes, magnetrons, crossed-field amplifiers, and gyrotrons. Artech House; 2011.

[45] O.Z. Sharaf, M.F. Orhan, An overview of fuel cell technology: Fundamentals and applications, Renewable and Sustainable Energy Reviews 32 (2014) 810-853. https://doi.org/10.1016/j.rser.2014.01.012

[46] H.G. Song, Y.N. Chun, Microwave gasification and oxy-steam combustion for using the biomass char, The Journal of Material Cycles and Waste Management 22 (2020) 176-186. https://doi.org/10.1007/s10163-019-00926-1

[47] A. Perna, M. Minutillo, A. Lubrano Lavadera, E. Jannelli, Combining plasma gasification and solid oxide cell technologies in advanced power plants for waste to energy and electric energy storage applications, Waste Management 73 (2018) 424-438. https://doi.org/10.1016/j.wasman.2017.09.022

[48] European Commission, EU Circular Economy Action Plan. https://ec.europa.eu/environment/circular-economy/, 2020 (accessed 25 April 2020). 